\title{
Profil zawartości WWA w eksploatowanych olejach smarowych i spalinach emitowanych z pojazdów z silnikiem benzynowym
}

\begin{abstract}
W artykule przedstawiono przegląd wyników badań nad zmianami profili zawartości toksycznych związków w eksploatowanych olejach smarowych i gazach spalinowych emitowanych z pojazdów z silnikiem benzynowym. W olejach silnikowych $w$ trakcie eksploatacji i w emitowanych spalinach oznaczano wielopierścieniowe węglowodory aromatyczne (WWA). Badano zmiany stężeń wybranych WWA, głównie benzo[a]antracenu, chryzenu, benzo[b] fluorantenu, benzo[j]fluorantenu, benzo[k]fluorantenu, benzo[e]pirenu, benzo[a]pirenu i dibenzo[ah]antracenu. Do oznaczenia zawartości WWA w próbkach wykorzystywany był głównie chromatograf gazowy sprzężony ze spektrometrem mas (GC/MS).
\end{abstract}

Słowa kluczowe: wielopierścieniowe węglowodory aromatyczne, WWA, oleje silnikowe, silnik benzynowy, emisja.

\section{The PAH's content profile in used engine oils and exhaust gases emitted from vehicles equipped with petrol engines}

\begin{abstract}
This paper presents the overview of the changing of toxic compounds content profile in used engine oils and exhausted gases emitted from vehicles equipped with petrol engines. Polycyclic Aromatic Hydrocarbons (PAH) were determined in used engine oils and emitted exhaust gases. The changes of chosen PAH's concentration determined were mainly: benzo[a]antracene, chryzene, benzo[b]fluoranthene, benzo[j]fluoranthene, benzo[k]fluoranthene, benzo[e]pirene, benzo[a]pirene, dibenzo[ah]anthracene. PAH were determined in samples mainly with the use of gas chromatograph coupled with a mass spectrometer detector (GC/MS).
\end{abstract}

Key words: Polycyclic Aromatic Hydrocarbons, PAH, engine oils, petrol engine, Spark Ignition Engine, emission.

Wielopierścieniowe węglowodory aromatyczne (WWA) stanowią grupę kilkudziesięciu związków chemicznych, zawierających w cząsteczce od trzech do kilkunastu pierścieni aromatycznych. Są one przedmiotem licznych badań ze względu na swoje kancerogenne, mutagenne i teratogenne właściwości. WWA to najlepiej poznana pod względem właściwości kancerogennych grupa związków, które znajdują się w środowisku bądź jako związki pochodzenia naturalnego (biosynteza, pożary, gazy i pyły wulkaniczne), bądź jako zanieczyszczenia powstałe w wyniku niecałkowitego spalania związków organicznych (procesy przemysłowe, spalanie odpadów, energetyka, spaliny samochodowe). Zasadniczo każdy proces związany z silnym ogrzewaniem lub niecałkowitym spalaniem związków organicznych może być źródłem emisji WWA. Stwierdzono, że nie występują one pojedynczo, lecz zawsze w mieszaninie. WWA należy zaliczyć do grupy tzw. kancerogenów pośrednich, które nie wywołują choroby nowotworowej bezpośrednio, ale dopiero po metabolicznym przekształceniu w organizmie do właściwych związków rakotwórczych. Ponadto wykazano na podstawie licznych badań toksykologicznych, że benzo[a]piren ma właściwości mutagenne. Własności fizykochemiczne wybranych WWA przedstawiono w tablicy 1 [7].

W związku z tym, że wiele WWA wykazuje własności kancerogenne i/lub mutagenne, oznaczane są ich zawartości w powietrzu, wodzie i glebie. Należy podkreślić, że powietrze jest elementem środowiska najbardziej narażonym na skażenie WWA. Jest ono równocześnie ośrodkiem, w którym 
Tablica 1. Wzory i właściwości fizyczne wybranych WWA [7]

\begin{tabular}{|l|c|c|c|c|c|}
\hline \multicolumn{1}{|c|}{ Związek } & $\begin{array}{c}\text { Wzór } \\
\text { sumaryczny }\end{array}$ & $\begin{array}{c}\text { Masa } \\
\text { cząsteczkowa }\end{array}$ & $\begin{array}{c}\text { Temperatura } \\
\text { topnienia } \\
{\left[{ }^{\circ} \mathrm{C}\right]}\end{array}$ & $\begin{array}{c}\text { Temperatura } \\
\text { wrzenia } \\
{\left[{ }^{\circ} \mathrm{C}\right]}\end{array}$ & $\begin{array}{c}\text { Prężność } \\
\text { par w 25 }{ }^{\circ} \mathrm{C} \\
{[\mathrm{kPa}]}\end{array}$ \\
\hline Fluoren & $\mathrm{C}_{13} \mathrm{H}_{10}$ & 166,23 & 116 do 118 & 293 do 295 & $8,7 \cdot 10^{-5}$ \\
\hline Antracen & $\mathrm{C}_{14} \mathrm{H}_{10}$ & 178,24 & 216 do 219 & 340 & $3,6 \cdot 10^{-6}$ \\
\hline Fenantren & $\mathrm{C}_{14} \mathrm{H}_{10}$ & 178,24 & 96 do 101 & 339 do 340 & $2,3 \cdot 10^{-5}$ \\
\hline Fluoranten & $\mathrm{C}_{16} \mathrm{H}_{10}$ & 202,26 & 107 do 111 & 375 do 393 & $6,5 \cdot 10^{-7}$ \\
\hline Piren & $\mathrm{C}_{16} \mathrm{H}_{10}$ & 202,26 & 150 do 156 & 360 do 404 & $3,1 \cdot 10^{-6}$ \\
\hline Benzo[a]antracen & $\mathrm{C}_{18} \mathrm{H}_{12}$ & 228,30 & 157 do 167 & 435 & $1,5 \cdot 10^{-8}$ \\
\hline Chryzen & $\mathrm{C}_{18} \mathrm{H}_{12}$ & 228,30 & 252 do 256 & 441 do 448 & $5,7 \cdot 10^{-10}$ \\
\hline Reten & $\mathrm{C}_{18} \mathrm{H}_{18}$ & 234,34 & 101 & 390 & $\sim 10^{-6}$ \\
\hline Benzo[b]fluoranten & $\mathrm{C}_{20} \mathrm{H}_{12}$ & 252,32 & 167 do 168 & 481 & $6,7 \cdot 10^{-8}$ \\
\hline Benzo[k]fluoranten & $\mathrm{C}_{20} \mathrm{H}_{12}$ & 252,32 & 198 do 217 & 480 do 481 & $2,1 \cdot 10^{-8}$ \\
\hline Perylen & $\mathrm{C}_{20} \mathrm{H}_{12}$ & 252,32 & 273 do 278 & 500 do 503 & $7,0 \cdot 10^{-10}$ \\
\hline Benzo[a]piren & $\mathrm{C}_{20} \mathrm{H}_{12}$ & 252,32 & 177 do 179 & 493 do 496 & $7,3 \cdot 10^{-10}$ \\
\hline Benzo[e]piren & $\mathrm{C}_{20} \mathrm{H}_{12}$ & 252,32 & 178 do 179 & 493 & $7,4 \cdot 10^{-10}$ \\
\hline Benzo[ghi]perylen & $\mathrm{C}_{22} \mathrm{H}_{12}$ & 276,34 & 275 do 278 & 525 & $1,3 \cdot 10^{-11}$ \\
\hline Dibenzo[ah]antracen & $\mathrm{C}_{22} \mathrm{H}_{14}$ & 278,35 & 266 do 270 & 524 & $1,3 \cdot 10^{-11}$ \\
\hline Koronen & $\mathrm{C}_{24} \mathrm{H}_{12}$ & 300,36 & 438 do 440 & 525 & $2,0 \cdot 10^{-13}$ \\
\hline
\end{tabular}

możliwa jest szybka i rozległa propagacja zanieczyszczeń. WWA mają wybitnie niekorzystny wpływ na człowieka zwłaszcza, że ich zwiększoną emisję obserwuje się na terenach miejskich i w okręgach przemysłowych o dużej gęstości zaludnienia, co zwiększa obszar populacji narażonej na ich oddziaływanie. Silniki spalinowe to jedno z istotnych źródeł skażenia środowiska naturalnego przez WWA, zwłaszcza w aglomeracjach miejskich. Emisji tych toksycznych substancji w spalinach samochodowych towarzyszy podczas eksploatacji różnego typu pojazdów jednoczesna emisja takich zanieczyszczeń jak: płyny eksploatacyjne z instalacji pojazdów, cząstki materiału okładzin hamulcowych, tarczy, sprzęgła, startego ogumienia, a także skażenie olejem przepracowanym. Innym problemem, na który zwrócono w ostatnich latach uwagę, jest emisja cząstek stałych (PM - particulate matter) także z silników benzynowych. W tablicy 2 zebrano dopuszczalne wartości emisji składników spalin w odniesieniu do postanowień norm emisji EURO dla pojazdów z silnikiem benzynowym. obowiązuje Rozporzadzenie Ministra Gospodarki i Pracy $z$ dnia 9 grudnia 2008 r., które określa najwyższe dopuszczalne stężenie związków aromatycznych w paliwach ciekłych. Dla benzyn stosowanych w pojazdach wyposażonych w silniki z zapłonem iskrowym maksymalna zawartość związków aromatycznych wynosi 35\% (V/V). Rozporzadzenie Ministra Gospodarki z dnia 2 lutego 2012 r. zmieniajace rozporzadzenie w sprawie wymagań jakościowych dla paliw ciektych wprowadziło ograniczenie dla olejów napędowych stosowanych w pojazdach wyposażonych w silniki z zapłonem samoczynnym maksymalnej ilości wielopierścieniowych węglowodorów aromatycznych (głównie dwu- i trójpierścieniowych) z 11 do $8 \%(\mathrm{~m} / \mathrm{m})$. Pomimo wdrożenia powyższych wymagań, w miejscach poboru prób powietrza usytuowanych w pobliżu dróg stwierdzono, że całkowita zawartość WWA była $2 \div 10$ razy wyższa niż na terenach pozbawionych infrastruktury drogowej. Natomiast wody spływające z dróg o nawierzchniach asfaltowych zawierały wysokie stężenia tych związków (rzędu $0,1 \mu \mathrm{g} / \mathrm{m}^{3}$ ). W czasie ulewnego deszczu stężenie WWA może chwilowo wzrosnąć nawet stukrotnie (odnotowano wzrost stężenia z 0,085 do $8,45 \mu \mathrm{g} / \mathrm{m}^{3}$ ) wskutek spłukiwania tych związków z nawierzchni dróg. Zawartość WWA w glebie zależy natomiast od wielkości opadu pyłów z powietrza oraz od rodzaju gleby warunkującej przebieg procesów biochemicznych. Stwierdzono, że koncentracja benzo[a]pirenu w glebach piaszczystych z obszaru wiejskiego, z dala od ośrodków przemysłowych, wynosi około $10 \mu \mathrm{g} / \mathrm{kg}$, a w glebach piaskowo-próchniczych (ogrodowych) z tego samego obszaru - około $100 \mu \mathrm{g} / \mathrm{kg}$.

Ze względu na małe wymiary, emitowane cząstki stałe (PM) utrzymują się długo w powietrzu i są łatwo wchłaniane przez układ oddechowy ludzi i zwierząt. Najczęściej są to stałe produkty niecałkowitego spalania paliwa, przy czy za najniebezpieczniejsze dla zdrowia uważa się właśnie wielopierścieniowe węglowodory aromatyczne, zaadsorbowane na emitowanych cząstkach stałych. W Polsce aktualnie

Tablica 2. Dopuszczalne wartości emisji składników spalin w odniesieniu do postanowień norm emisji EURO dla pojazdów z silnikiem benzynowym [3]

\begin{tabular}{|c|c|c|c|c|c|c|}
\hline $\begin{array}{c}\text { Emisja } \\
{[\mathrm{g} / \mathrm{km}]}\end{array}$ & EURO 1 & EURO 2 & EURO 3 & EURO 4 & EURO 5 & EURO 6 \\
\hline $\mathrm{CO}$ & 2,72 & 2,2 & 2,30 & 1,00 & 1,000 & 1,000 \\
\hline $\mathrm{HC}$ & - & - & 0,20 & 0,10 & 0,100 & 0,100 \\
\hline $\mathrm{NO}_{\mathrm{x}}$ & - & - & 0,15 & 0,08 & 0,060 & 0,060 \\
\hline $\mathrm{HC}+\mathrm{NO}_{\mathrm{x}}$ & 0,97 & 0,5 & - & - & - & - \\
\hline $\mathrm{PM}$ & - & - & - & - & 0,005 & 0,005 \\
\hline
\end{tabular}


Z kolei inne badania wykazały, że w glebie w pobliżu zakładów petrochemiczno-rafineryjnych stężenie benzo[a]pirenu wynosiło około $15000 \mu \mathrm{g} / \mathrm{kg}$, natomiast w odległości $5 \mathrm{~km}$ od tych zakładów spadało poniżej $200 \mu \mathrm{g} / \mathrm{kg}[5,6]$.

Stały rozwój konstrukcji silników spalinowych, zmierzający do ograniczenia negatywnego oddziaływania emisji na środowisko naturalne, wiąże się jednocześnie ze wzrostem wysilenia tych jednostek. Obecne tendencje do konstruowania silników o mniejszych rozmiarach powodują, że są one narażone na większe obciążenia cieplne i mechaniczne. Prawidłowe ich użytkowanie zależy również od zastosowania wysokojakościowych płynów eksploatacyjnych, wśród których ogromną rolę odgrywają oleje silnikowe. Oleje silnikowe w czasie pracy ulegają działaniom przede wszystkim dwóch czynników: wysokiej temperatury, a także obecności powietrza, które zawiera tlen oraz różnego rodzaju zanieczyszczenia. W czasie pracy silnika do oleju przedostają się gazy spalinowe wraz z częścią niedopalonego paliwa. Wydzielające się podczas pracy silnika ciepło, kontakt z paliwem i produktami jego spalania, przy obecności tlenu z powietrza, powodują degradację podstawowego składnika olejów silnikowych - węglowodorów. Towarzyszące temu inne przemiany chemiczne i mechanochemiczne (np. ścinanie polimerów) powodują obniżenie zawartości dodatków uszlachetniających, wprowadzonych do oleju silnikowego dla nadania mu wymaganych cech jakościowych. Zatem w czasie eksploatacji obserwuje się zarówno zmiany charakteru chemicznego oleju silnikowego, jak i towarzyszące im zmiany jego jakości. W wyniku oddziaływania wysokich temperatur następuje rozkład (piroliza) lub przegrupowanie (pirosynteza) struktur węglowodorowych obecnych w oleju silnikowym. W wyniku tych reakcji powstają wielopierścieniowe związki aromatyczne (WZA, ang. PAC - Polycyclic Aromatic Compounds), do których zalicza się wielopierścieniowe węglowodory aromatyczne i węglowodory heterocykliczne (zawierające $\mathrm{w}$ swej strukturze dodatkowo pojedynczy atom siarki, azotu lub tlenu). Ma to wpływ na zwiększenie stopnia szkodliwości związków emitowanych w spalinach. Dalsze przemiany strumienia emitowanych substancji mogą nastąpić w układzie wydechowym. Niska temperatura gazów spalinowych i mała zawartość w nich tlenu sprzyjają emisji niezmienionych chemicznie węglowodorów. W czasie eksploatacji oleju, także w wyniku różnego rodzaju przemian termooksydacyjnych i fizykochemicznych (polimeryzacja, kondesacja), wzrasta w nim zawartość substancji toksycznych. Stopień toksyczności eksploatowanego oleju silnikowego zależy od warunków i czasu jego stosowania, mających wpływ na wielkość zanieczyszczenia oleju eksploatowanego produktami niepełnego spalania paliwa. Wzrost toksyczności oleju postępuje wraz z wydłużeniem czasu jego eksploatacji, głównie wskutek zwiększenia w oleju stężenia WWA [10, 14, 15].
Silnikowe oleje smarowe zanieczyszczają środowisko już w czasie ich produkcji oraz na wszystkich etapach ich stosowania: podczas transportu do użytkowników, długiego magazynowania, w trakcie pracy w silniku, a także przy zbiórce i utylizacji po zakończeniu okresu eksploatacji. W każdym z wymienionych etapów stopień wpływu olejów na środowisko jest różny i zależny od trzech głównych czynników: składu chemicznego oleju, warunków pracy (przede wszystkim jego temperatury roboczej) w urządzeniu (silniku spalinowym) i sposobu obchodzenia się z olejami. Decydujący jest skład chemiczny oleju, determinujący najbardziej ekologiczny i ekonomicznie uzasadniony sposób utylizacji przepracowanego oleju w celu ochrony środowiska naturalnego. Oleje przepracowane są wysoce toksyczne i mają złożony skład chemiczny, zawierają wielopierścieniowe węglowodory aromatyczne, a stężenie benzo[a]pirenu jest przez niektóre akty legislacyjne uznawane za miarę rakotwórczości oleju przepracowanego. Dodatkowo związki wchodzące w skład olejów przepracowanych mogą reagować między sobą, tworząc często niebezpieczne dla środowiska i człowieka substancje. W czasie pracy silnika następują zmiany nie tylko bazy węglowodorowej danego oleju smarowego; przemianom do innej struktury chemicznej i fizycznej ulegają także dodatki uszlachetniające. Oleje, które utraciły swoje właściwości użytkowe, zgodnie z Rozporzadzeniem Ministra Środowiska z dnia 27 kwietnia 2001 roku w sprawie katalogu odpadów z wyodrębnieniem odpadów niebezpiecznych (Dz. U. nr 62, poz. 623 i Dz. U. nr 112, poz. 1206, z dnia 27 kwietnia 2001 r.) zaliczane są do odpadów niebezpiecznych [8,9].

Prace badawcze prowadzone w ostatnich dziesięcioleciach wykazały jednoznacznie, że wielopierścieniowe węglowodory aromatyczne powstają podczas pracy silnika i gromadzą się w oleju smarowym. Eksploatowany olej z silnika benzynowego jest potencjalnie kancerogenny. Prowadzono badania w kierunku ustalenia korelacji pomiędzy przebiegiem silnika (czasookresem pracy oleju w silniku) a aktywnością kancerogenną oleju. Stwierdzono związek pomiędzy liczbą przypadków nowotworów skóry w grupie doświadczalnej myszy a przebiegiem samochodów stosujących badane oleje silnikowe. Stężenie WWA także było większe w olejach po dłuższym okresie eksploatacji, ale nie stwierdzono korelacji pomiędzy liczbą przypadków nowotworów spowodowanych eksploatowanym olejem i zawartością WWA. Zauważono, że zawartość WWA w oleju gwałtownie wzrasta przy przebiegu pojazdu z silnikiem benzynowym powyżej $5000 \mathrm{~km}$, a olej pobrany po ponad $20000 \mathrm{~km}$ wykazuje wyższą kancerogenność niż olej po $10000 \mathrm{~km}$. Zaobserwowana kancerogenność wynika nie tylko z zawartości WWA. Olej po przebiegu $20000 \mathrm{~km}$, o niższej koncentracji WWA niż badany równolegle olej pobrany po $10000 \mathrm{~km}$, okazał się zdecydowanie bardziej kancerogenny [10]. Przykładowe wyniki oznaczeń 


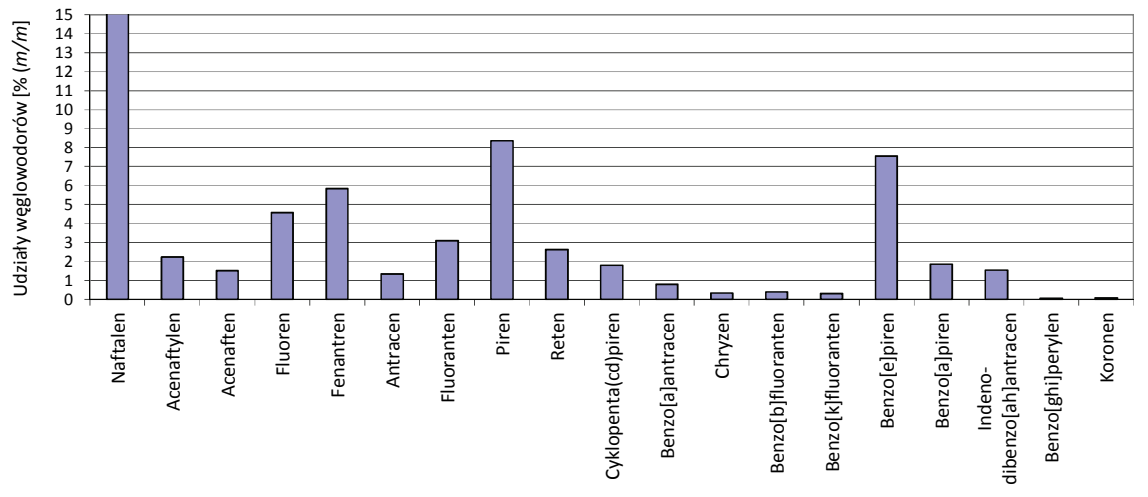

Rys. 1. Profil wybranych WWA w eksploatowanym oleju z silnika benzynowego [1]
Do identyfikacji i oznaczania śladowych ilości WWA wykorzystywana jest najczęściej metoda spektrometrii mas w sprzężeniu z chromatografią gazową (GC/MS - Gas Chromatography/Mass Spectrometry). Technika GC/MS umożliwia rejestrację widma mas związku lub związków eluowanych w obrębie pojedynczego piku chromatograficznego. Cechuje ją wysoka powtarzalność wyników. Różnica jednostki masy atomowej pozwala na odróżnienie obserwowanych jonów, co umożliwia w pew- stężeń wybranych WWA w eksploatowanym oleju z silnika benzynowego przedstawiono $\mathrm{w}$ formie profili na rysunku 1 [1].

Kompleksowa ocena wpływu WWA obecnych w eksploatowanych olejach silnikowych na środowisko naturalne jest stosunkowo trudna. Zmienność warunków powstawania WWA oraz przebieg reakcji wtórnych w kontakcie $\mathrm{z}$ atmosferą, światłem słonecznym, a także innymi zanieczyszczeniami środowiska, powodują dużą różnorodność składu mieszaniny WWA i ich toksycznych właściwości. Klasyczne podejście statystyczne, polegające na określeniu stężeń poszczególnych analitów i oszacowaniu niepewności ich oznaczeń, nie daje pełnej informacji o możliwych zagrożeniach dla środowiska naturalnego. Z tego względu pojawiło się pojęcie profilu określonych grup zanieczyszczeń, przez co rozumie się tworzenie map zagrożeń, łączących okres czy obszar ich występowania. Ogólnie rzecz ujmując, profilami są zwykle graficzne przedstawienia zawartości zanieczyszczeń atmosferycznych w funkcji czasu i miejsca. Natomiast profile zawartości substancji kancerogennych tworzących się podczas pracy silnika spalinowego są to obrazy zależności ilości i rodzaju WWA, uzyskane podczas analizy eksploatowanego oleju silnikowego, w zależności od warunków pracy silnika i właściwości stosowanych paliw czy olejów smarowych.

Przykładowe stężenia WWA w formie profili w gazach spalinowych z silnika benzynowego, w zależności od rodzaju pojazdu, przedstawiono na rysunku 2.

Badanie koncentracji WWA można prowadzić wieloma metodami. Powszechnie stosuje się do rozdzielania i ilościowego oznaczania techniki chromatograficzne, takie jak: chromatografia cienkowarstwowa (TLC - Thin Layer Chromatography), wysokorozdzielcza chromatografia gazowa (HRGC - High Resolution Gas Chromatography) i wysokosprawna chromatografia cieczowa (HPLC High Performance Liquid Chromatography). nych warunkach przypisanie ich do określonych grup związków. Osiągana jest przy tym bardzo duża czułość i niska granica wykrywalności. Z tego względu GC/MS zajmuje szczególne miejsce w identyfikacji i oznaczaniu związków

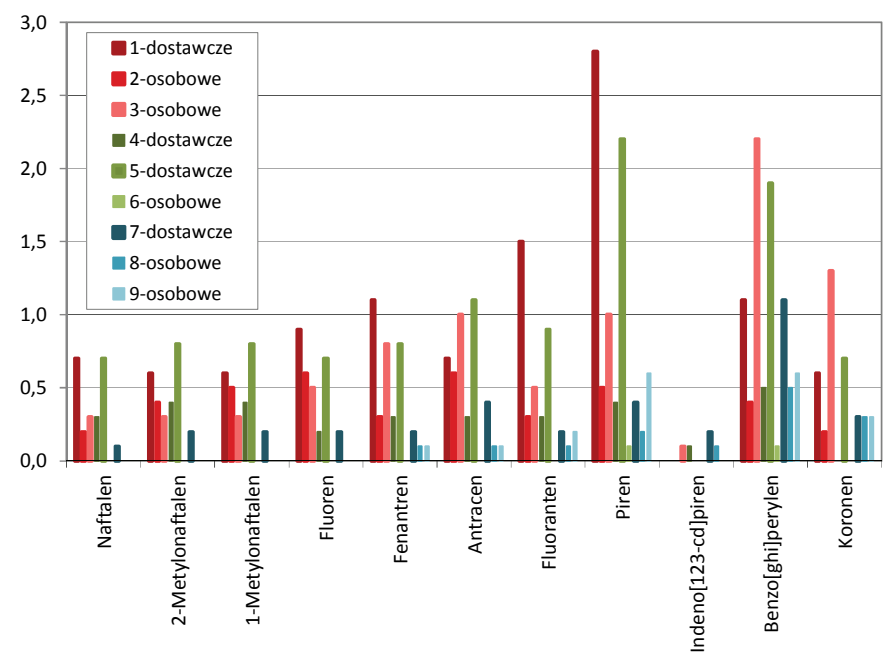

Rys. 2. Profile zawartości WWA w gazach spalinowych $\mathrm{z}$ silnika benzynowego w zależności od rodzaju pojazdu i ilości emitowanych cząstek stałych; $1 \div 3$ emisja PM > $30 \mathrm{mg} / \mathrm{km}, 4 \div 6$ emisja PM $>10 \mathrm{mg} / \mathrm{km} \mathrm{i} 7 \div 9<10 \mathrm{mg} / \mathrm{km} \mathrm{[4]}$

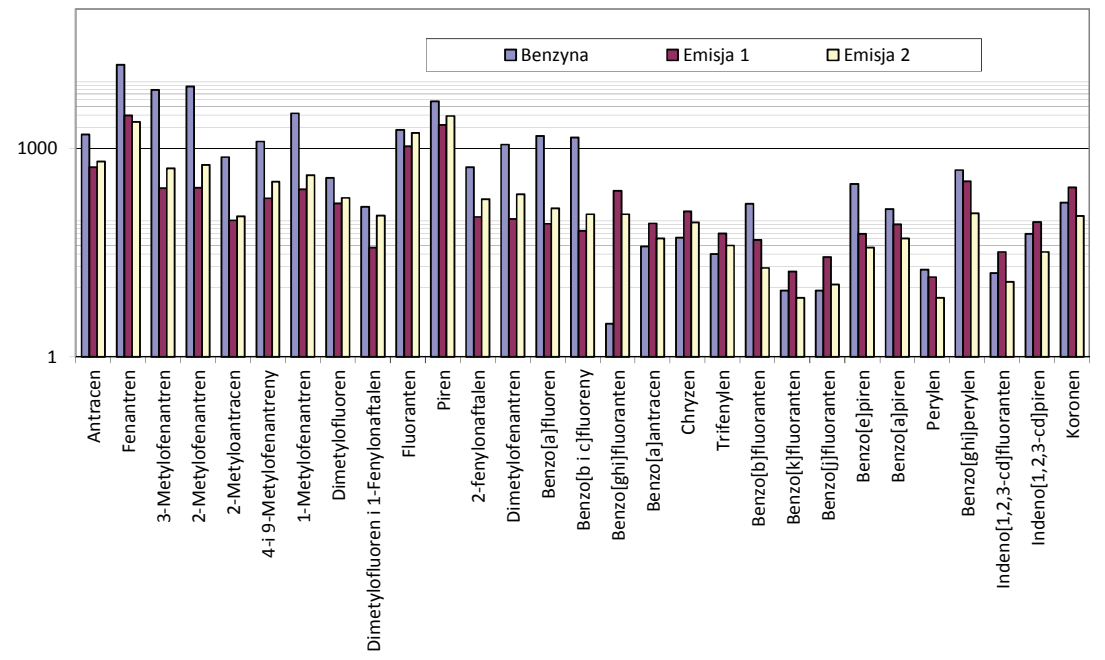

Rys. 3. Profil stężeń WWA [ $\mu \mathrm{g} / \mathrm{l}$ spalonego paliwa] w benzynie i emitowanych gazach spalinowych z dwóch pojazdów nią zasilanych (oznaczenia: emisja 1 i 2) [2] 
organicznych. Połączenie chromatografii gazowej ze spektrometrią mas stworzyło jedno z najbardziej skutecznych narzędzi w analizie skomplikowanych mieszanin związków organicznych. Po rozdzieleniu mieszaniny w bloku chromatografu gazowego do analizatora spektrometru mas wprowadzane są kolejno czyste związki lub mieszaniny, co najwyżej kilku składników o odpowiedniej lotności. Stosując tylko analizę chromatograficzną w przypadku badania mieszanin wieloskładnikowych o niewielkim stężeniu analitów, często nie uzyskuje się wystarczającego rozdziału chromatograficznego, a także nie ma pewności, czy dany sygnał odpowiada określonemu związkowi. Natomiast użycie GC/MS umożliwia identyfikację wielu składników badanych substancji i ich oznaczenie ilościowe - nawet przy bardzo niskim poziomie stężeń $[12,13]$. Szerokie możliwości badawcze GC/MS $\mathrm{w}$ analizie profili WWA w benzynie, a także w gazach spalinowych emitowanych z dwóch pojazdów (oznaczenia: emisja 1 i 2) nią zasilanych, przedstawiono na rysunku 3 [2].

\section{Podsumowanie}

Silniki benzynowe są jednym z istotnych źródeł skażenia środowiska naturalnego przez WWA, zwłaszcza w obszarach o wysokiej gęstości zaludnienia. Zastosowanie GC/MS do oznaczania WWA w eksploatowanych olejach i emitowanych spalinach z silników benzynowych sprawia, że dzięki takiemu połączeniu technik osiągana jest bardzo duża czułość i niska granica wykrywalności. Oznaczając WWA w próbkach eksploatowanych olejów silnikowych, zaobserwowano stały trend w profilu zawartości WWA - w miarę wzrostu przebiegu pojazdów rosło stężenie WWA. Profil wzajemnych stosunków masowych WWA nie wykazywał już tak charakterystycznych zmian, na co ma wpływ wiele czynników wnoszących niepewność do oznaczenia analitycznego WWA, jak i niepowtarzalnej pracy silnika czy odmiennych warunków eksploatacji silników. Badanie profili zawartości WWA poszerza zbiór informacji o zmianach, jakim ulegają oleje smarowe w czasie pracy w silniku benzynowym i o obserwowanym w związku z nimi wzmożeniu toksyczności oleju przepracowanego.

Prosimy cytować jako: Nafta-Gaz 2016, nr 8, s. 666-670, DOI: 10.18668/NG.2016.08.12

Artykuł nadesłano do Redakcji 10.11.2015 r. Zatwierdzono do druku 7.05.2016 r.

Artykuł powstał na podstawie pracy statutowej pt. Analiza profili toksycznych zwiazków w olejach smarowych, eksploatowanych w pojazdach z silnikiem benzynowym - praca INiG - PIB na zlecenie MNiSW; nr zlecenia: 0004/TA/15/01, nr archiwalny DK-4100/0004/15.

\section{Literatura}

[1] Chen S. J., Jian W. J., Huang Y. Ch.: PAHs and aerosols carbons in the exhaust of gasoline powered engine. Aerosols and Air Quality Research 2001, vol. 1, nr 1, s. 57-67.

[2] Diesel and Gasoline Engine Exhaust and Some Nitroarenes. IARC Monographs on the Evaluation of Carcinogenic Risks to Human 2014, vol. 105

[3] Europejski standard emisji spalin; https://pl.wikipedia.org/wiki/ Europejski_standard_emisji_spalin (dostęp: 15.04.2016).

[4] Fujita E. M., Campbell D. E., Zielinska B.: Chemical analysis of lubrication oil samples from a study to characterize Exhaust emission from Light-Duty gasoline vehicles In the Kansas City Metropolitan Area. Final Technical Report, Desert Research Institute, 2006; http://www.crcao.org/reports/recentstudies2007/E-69a/E-69a Final Report.pdf (dostep: 15.04.2016).

[5] Janicka A., Walkowiak W.: Emisja lotnych zwiąków organicznych $i$ wielopierścieniowych węglowodorów aromatycznych z silnika zasilanego biopaliwem. Silniki Spalinowe 2007, nr SC3, s. 46-53.

[6] Khalili N. R., Scheff A., Holsen T. M.: PAH source fingerprinting for coke ovens, diesel and gasoline engines, highway tunnels, and wood combustion emissions. Atmospheric Environment 1995, vol. 29, nr 4, s. 533-542.

[7] Łebkowska M.: Toksykologia środowiska. Oficyna Wydawnicza Politechniki Warszawskiej, 1999.

[8] Magiera J.: Rerafinacja olejów przepracowanych. Wydawnictwo Naukowo-Techniczne, 2006, s. 57-61.

[9] Markiewicz M.: Przepracowane oleje smarowe - ich zbiórka i zagospodarowanie. Paliwa, Oleje i Smary w Eksploatacji 1999, nr 63, s. 5-9.

[10] Merkisz J.: Tendencje rozwojowe silników. Silniki Spalinowe/ Combustion Engines 2004, vol. 118, nr 1, s. 28-39.

[11] Monier V., Labouze E.: Critical Review of Existing Studies and Life Cycle Analisys on the Regeneration and Incineration of Waste Oils. Final Raport, December 2001.

[12] Sharma K., Sharma S. P., Lahiri S. C.: Characterization and Identification of Petroleum Hydrocarbons and Biomarkers by GC-FTIR and GC-MS. Petroleum Science and Technology 2009, vol. 27, s. 1209-1226.

[13] Suder P., Silberring J.: Spektrometria mas. Wydawnictwo Uniwersytetu Jagiellońskiego. Kraków 2006.

[14] Urzędowska W., Stępień Z.: Eksploatacja olejów smarowych $w$ silnikach z zaptonem iskrowym, zasilanych LPG. Nafta-Gaz 2009, nr 8, s. 624-630.

[15] Urzędowska W., Stępień Z.: Wybrane zagadnienia dotyczące zmian właściwości silnikowego oleju smarowego w eksploatacji. Nafta-Gaz 2012, nr 12, s. 1102-1110.

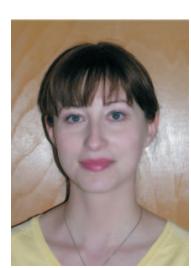

Mgr Xymena BADURA

Asystent w Zakładzie Analiz Naftowych. Instytut Nafty i Gazu - Państwowy Instytut Badawczy ul. Lubicz 25 A

31-503 Kraków

E-mail: badura@inig.pl 